\title{
Beskrywing, modellering en dok-studies van Plasmodium falciparum kinase PfCDPK4
}

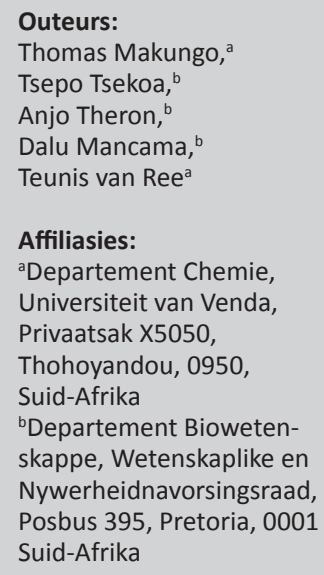

Korresponderende outeur: Teunis van Ree

E-pos:

Teuns.VanRee@univen.ac.za; teunsvanree@gmail.com

Datums:

Ontvang: $\quad 18 / 06 / 18$

Aanvaar: $\quad 19 / 02 / 19$

Gepubliseer: $11 / 04 / 19$

Hoe om hierdie artikel aan te haal:

Thomas Makungo, Tsepo Tsekoa, Anjo Theron, Dalu Mancama, Teunis van Ree, Beskrywing, modellering en dok-studies van Plasmodium falciparum kinase PfCDPK4, Suid-Afrikaanse Tydskrif vir Natuurwetenskap en Tegnologie 38(1) (2019). https://doi.org/10.36303/ SATNT.2019.38.1.677

An English copy of this paper is available online at http://www.satnt.ac.za/ index.php/satnt/article/ view/677

Kopiereg:

(C) 2019. Authors.

Licensee: Die SuidAfrikaanse Akademie vir Wetenskap en Kuns. Hierdie werk is onder die Creative Commons Attribution License gelisensieer.

\begin{abstract}
Met die toenemende voorkoms van weerstandige Plasmodium stamme het die beheer van malaria-voorkoms en -mortaliteit weer op die voorgrond getree. Nuwe teikens en antimalariamiddels wat effektief is teen weerstandige malaria-parasiete word dus dringend benodig. Kalsium-afhanklike proteïenkinases (calcium dependent protein kinases CDPKs) is betrokke by die beheer van ' $n$ aantal biologiese prosesse in die malaria-parasiet, Plasmodium falciparum, met CDPK4 die belangrikste ensiem in hierdie klas. In hierdie studie is die struktuur van PfCDPK4 gebruik as templaat vir die soeke na nuwe malariamiddels. Die PfCDPK4 modelstruktuur is deur middel van homologiemodellering gegenereer en die stereochemiese kwaliteit gevalideer. Die molekulêre modelleringbenadering deur middel van in silico sifting teen die teiken-molekuul PfCDPK4 het ' $n$ beskeie biblioteek van 20000 chemiese verbindings ingesluit, asook 'n aantal aktiewe natuurprodukte en kliniesgoedgekeurde kinase-inhibeerders. In silico sifting van die Biofocus biblioteek teen PfCDPK4 het 26 verbindings opgelewer; in vitro sifting het bevestig dat drie van hierdie verbindings matig aktief is teen Plasmodium falciparum NF54, met persentasie inhibisie tussen $42 \%$ en $47 \%$.
\end{abstract}

Characterization, modelling and docking studies of Plasmodium falciparum kinase PfCDPK4: The increasing incidence of Plasmodium strains that are resistant to current frontline antimalarial drugs has become one of the greatest challenges of controlling malaria incidence and mortality. There is, therefore, an urgent need to develop novel targets and antimalarial drugs that are effective against drug-resistant malarial parasites. At the same time the need to develop antimalarial drugs that furthermore prevent disease transmission, has become an increasingly important consideration. Calcium dependent protein kinases (CDPKs) regulate a variety of biological processes in the malaria parasite Plasmodium falciparum, CDPK4 being of prime importance in Plasmodium biology. In this study the structure of PfCDPK4 was used as a template in the discovery of malaria drug leads. The model structure of PfCDPK4 was generated by homology modelling, and model validation confirmed that the model of PfCDPK4 is of stereochemical quality. The molecular modelling approach of in silico screening against the target molecule PfCDPK4 utilized a large library of chemical compounds, some natural chemical compounds, and clinically approved kinase inhibitors. In silico screening of the Biofocus library against PfCDPK4 resulted in twenty-six compounds being identified; in vitro screening confirmed that three of these compounds exhibit moderate antimalarial activity against the NF54 strain of Plasmodium falciparum, with the percentage inhibition ranging between $42 \%$ and $47 \%$.

\section{Inleiding}

Die toenemende voorkoms van Plasmodium variante wat weerstandig is teen die huidige eerste-linie antimalariamiddels sorg dat malaria steeds 'n globale openbare gesondheiduitdaging bly. Daar is steeds behoefte aan nuwe antimalaria-middels wat aktief sal wees teen weerstandige parasiete. Die siekte word oorgedra deur geïnfekteerde vroulike Anopheles muskiete (Biamonte et al., 2013; Dorin-Semblat et al., 2013; Lounnas et al., 2013). Vyf malaria spesies veroorsaak die siekte in mense, maar Plasmodium falciparum veroorsaak die dodelikste infeksies (Anastassiadis et al., 2011; Klein, 2013; Vidadala et al., 2014; WHO, 2017), veral in Wes-, Oos- en Sentraal-Afrika (Murray et al., 2012). Meer as 216 miljoen mense word jaarliks aan die risiko van malaria-infeksie blootgestel, daarvan $90 \%$ in Afrika suid van die Sahara, met veral kinders en swanger vroue wat kwesbaar is (WHO, 2016).

Die bekendste antimalaria-middels chlorokien (CQ), sulfadoksien-pirimetamien (SP) en artemisinien is hoogs doeltreffend teen die eritrosiet-stadium van $P$. falciparum infeksies (Klein, 2013). P. falciparum weerstandigheid teen CQ, meflokien en SP het egter teen die 1960s 
in die Kambodja-Thailand grensgebied begin ontwikkel en vandaar geleidelik vanaf die Mekong delta na Afrika versprei. Studies van 2001 tot 2009 het weerstandigheid in Kambodja en Thailand bevestig (WHO, 2017), en het aanleiding gegee tot die globale plan vir die beperking van artemisinien-weerstand (Global Plan for Artemisinin Resistance Containment - GPARC) (WHO, 2011). Die huidige benadering van artemisinien kombinasieterapie (ACT) slaag ook steeds minder daarin om malaria-oordrag van mens na muskiet te verhinder (Ojo et al., 2012).

Proteïenkinases kataliseer die oordrag van fosfaat vanaf ATP na spesifieke aminosuur-residue op proteïen-teikens of substrate, en beïnvloed die aktiwiteit, stabiliteit en interaksie van die teikenproteïen(e) met ligande (Lim et al., 2012). Hierdie kritieke rol wat proteïenkinases in sellulêre kommunikasie speel, en die bewese teenwoordigheid van ATP-aktiewe posisies wat deur chemise verbindings bereik en dus geïnhibeer kan word, maak die proteïenkinases 'n belowende klas as terapeutiese teikens (Anastassiadis et al., 2011). Die CDPKs word direk deur kalsium gereguleer en beïnvloed ' $n$ verskeidenheid biologiese prosesse in die malariaparasiet (Kumar et al., 2017). CDPKs is teenwoordig in $P$. falciparum, plante, en sommige eensellige organismes (Ranjan et al., 2009). Hierdie ensieme en verwante homoloë kom nie in die mens voor nie en is dus ideale teikens vir geneesmiddels. In Plasmodium funksioneer verskillende CDPKs tydens verskillende stadia in die parasiet se lewensiklus (Chapman et al., 2013).

CDPK4 word in die gametosietstadium van die malaria parasiet uitgedruk (Bansal et al., 2013). Dit is 'n belangrike seinmolekuul vir die transisie na mikrogameet- en makrogameetvorms wat saamsmelt om 'n sigoot te vorm (Billker et al., 2004; Ranjan et al., 2009). Die Plasmodium CDPK4 vorm dus 'n belangrike skakel in die malarialewensiklus en transmissie (Ojo et al., 2012, 2014; Tewari et al., 2010). Genoom-inligting dui daarop dat Plasmodium berghei CDPK4 (PbCDPK4) homoloog is met Plasmodium falciparum CDPK4 (PfCDPK4) (91\% gemeenskaplike aminosure en $97 \%$ ooreenkoms) en Toxoplasma gondii CDPK1 (TgCDPK1) (met 73\% gemeenskaplike aminosure en $88 \%$ ooreenkoms) (Billker et al., 2004). PbCDPK4 is essensieel vir die parasiet se seksuele ontwikkelingsfase in die muskiet (Dorin-Semblat et al., 2013; Lounnas et al., 2013; WHO, 2017), en waarskynlik speel PfCDPK4 dieselfde rol. Die ontdekking van verbindings wat CDPK4 inhibeer sal dus 'n belangrike bydrae maak tot die bekamping van malaria. 'n Geneties-chemiese benadering het reeds PfCDPK4 as 'n moontlike teiken vir nuwe geneesmiddels gevalideer (Ojo et al., 2014).

PfCDPK4 word in die Plasmodium gameet/gametosietstadium uitgedruk en onderdrukking van die CDPK4 geen veroorsaak ernstige defekte in die parasiet se seksuele reproduksie (Ranjan et al., 2009). Die ensiem en sy homoloë is ook afwesig in die mens, sodat PfCDPK4 ' $n$ belowende teiken is vir gametosietstadium parasiete en dus transmissie van die siekte. Die struktuur van PfCDPK4, veral die kinase-domein, kan dus benut word om nuwe middels teen malaria te vind deur chemiese verbindings of inhibitore van die teiken-ensiem te ontwerp. Om hierdie idee te evalueer, het ons in hierdie studie ' $n$ beskeie biblioteek van chemiese verbindings in silico gesif vir moontlike aktiwiteit teen die teikenensiem, PfCDPK4. 'n Homologie modelstruktuur van PfCDPK4 is gebruik om moontlik aktiewe antimalariaverbindings te vind, en om die PfCDPK4 model as 'n teiken vir ontwikkeling van nuwe geneesmiddels te valideer. Inligting verkry deur in silico virtuele sifting is vervolgens gebruik om 'n versameling verbindings te identifiseer vir in vitro sifting teen ' $n$ P. falciparum kultuur en het 'n aantal belowende verbindings opgelewer vir moontlike verdere geneesmiddelontwikkeling.

\section{Materiaal en metodes} Molekuulmodellering van PfCDPK4

\section{Struktuurvoorspelling van PfCDPK4 deur molekuul- modellering}

Die aminosuurvolgorde van die kinase- of ATPbindingsdomein van PfCDPK4 is verkry van die UniProt Knowledgebase (UniProtKB) met Uniprot ID Q8IBS5 (UniProt Consortium, 2012). 'n Drie-dimensionele struktuur van PfCDPK4 is voorheen vasgestel deur middel van homologie-modellering gebaseer op die kristalstruktuur van die TgCDPK1:BKI-1 kompleks (Ojo et al., 2012). In die huidige studie is die 3D struktuur bepaal deur die aminosuurvolgorde van PfCDPK4 self as 'n soekterm te gebruik om 'n templaatstruktuur in die Protein Data Bank (PDB) te vind deur middel van 'n BLAST soektog (Altschul et al., 1997) met Discovery Studio 3.5 (Accelrys, 2012). Die BLAST soekprotokol is gebruik om 'n soektog binne die PDB_nr95 sekwensdatabasis in Discovery Studio te doen, met BLOSUM62 as substitusie/vergelyking matriks. 'n Templaat baie na aan die PfCDPK4 aminosuurvolgorde was weereens die kinase of ATP-bindingdomein TgCDPK1 (PDB Id: 3ma6) van die eensellige parasiet Toxoplasma gondii. Die drie-dimensionele TgCDPK1 struktuur is in die RCSB Protein Data Bank gevind (Deshpande et al., 2005).

Die Align 123 toepassing van Discovery Studio 3.5 is gebruik om die aminosuurvolgorde van PfCDPK4 met die TgCDPK1 volgorde te vergelyk. Die gebruik van 'n gewysigde CLUSTAL W (Thompson et al., 1994) algoritme, MODELER 9v8 (Šali et al., 1995), en die Build Homology Model protokol het 20 modelle opgelewer. Hierdie 20 modelle is met behulp van die Verify Protein (MODELER) protokol en die Verify Protein (Profiles-3D) protokol geëvalueer om die beste model te bepaal. Die DOPE (Discrete Optimized Protein Energy) telling is vir elke proteïenstruktuur bereken om die verkillende moontlike konformasies te vergelyk. 'n Laer DOPE telling beteken 'n beter kwaliteit model is gevind (Accelrys, 2012; Shen \& Šali, 2006). Die model proteïenstruktuur met die laagste DOPE telling en hoogste Verify telling is gebruik vir verdere verbetering en validering. 


\section{PfCDPK4 modelstruktuurverfyning en validering vir stereochemiese kwaliteit}

Die gekose modelstruktuur (PfCDPK4.F06) is verbeter deur 'n soektog vir lae-energie konformasies van lus-strukture met die Loop Refinement toepassing, gebaseer op CHARMm molekulêre meganika (Brooks et al., 1983; Karplus, 2003). Proteïenlusse is buigsame gebiede op proteïenoppervlaktes (Tang et al., 2014) en is dele van die polipeptied sonder sekondêre struktuur (Regad et al., 2010). Vir elke lus wat gekies is, is verskeie lae-energie konformasies onder 'n energie-drumpel van $20 \mathrm{kcal} / \mathrm{mol}$ gegenereer en die beste model is gevind deur middel van die DOPE en Verify tellings van die verskillende konformasies te vergelyk. Die verbeterde modelle is verder ondersoek deur middel van die Verify Protein (MODELER) en Verify Protein (Profiles-3D) toepassings. Die volgende aminosure is só aangepas: Glu132-Ile140, Gly196-Asn204, Leu55-Lys62, Met54-Lys62, Asn117-Lys125, Lys33-Glu43, Leu55-Lys62, Gly215-Leu221, His151-Lys157, Val119-Pro126, Met240Ser248, Phe152-Lys157, Asp78-Gly82, Lys33-Asp41, Ile144Gly147, Asp19-His24, Lys225-Ser228, Gly9-Phe11 en Asp69-Asn71. Die finale model is gevalideer deur gebruik van PROCHECK (Arnold et al., 2006, 2009; Laskowski et al., 1993; http://swift.cmbi.ru.nl/servers/html/ index.html) verkry vanaf die SWISS-MODEL Workspace webtuiste (http://swissmodel.expasy.org/workspace/). Die Ramachandran Plot (Ramachandran et al., 1963) is gebruik om die stereochemiese kwaliteit van die finale PfCDPK4 model te analiseer (Hovmoller et al., 2002).

\section{Teiken en biblioteekvoorbereiding}

\section{PfCDPK4 model-optimering en bindingposisie}

Die PfCDPK4 modelstruktuur is voorberei deur middel van die Prepare protein protokol in Discovery Studio 3.5 (Accelrys), wat oorblywende probleme in die proteïenstruktuur oplos met stappe soos protonering, standardisering van atoomname, en eliminering van alternatiewe konformasies.

Die bindingposisie is afgelei van die reseptor (PfCDPK4) se holruimtes deur middel van 'n uitvee-algoritme (Kang et al., 2017; Taha et al., 2014; Venkatachalam et al., 2003).

\section{Voorbereiding en optimering van die Biofocus en NSV biblioteke en bekende kinase-inhibitore}

Drie versamelings van verbindings is in hierdie ondersoek gebruik, nl. die Biofocus biblioteek van 20000 verbindings, 'n kinase-inhibitor versameling bestaande uit 'n klein subversameling van 13 klinies-bewese (FDAgoedgekeurde) verbindings (Zhao et al., 2013), en 'n versameling van 28 Natuurlike en Sintetiese Verbindings (NSV) met bekende of vermoede antimalaria-aktiwiteit. Verbindings van die Biofocus en NSV-versamelings is gefiltreer met behulp van Lipinski reëls (Lipinski et al., 1997) in Discovery Studio. Hierdie verbindings asook die kinase-inhibitore is geoptimeer deur middel van die Prepare Ligands protokol. Toutomere en isomere is gegenereer en duplikate verwyder.

\section{Virtuele en in vitro sifting van klein molekule teen die moontlike teiken PfCDPK4}

\section{Virtuele sifting van die Biofocus biblioteek teen die PfCDPK4 3D modelstruktuur}

Die 83707 voorbereide ligande van die Biofocus biblioteek teen die voorbereide PfCDPK4 struktuur is gesif deur middel van 'n CHARMm-gebaseerde kragveld in die LibDock toepassing van Discovery Studio 3.1 (Yu et al., 2013).

\section{Dok van bekende kinase-inhibitore en NSVs aan die PfCDPK4 3D modelstruktuur}

Die 36 verbindings wat verkry is deur optimering van die 13 bewese kinase-inhibitore, sowel as die 28 NSVs, is teen die voorbereide PfCDPK4 gesif deur middel van die CHARMm-gebaseerde CDOCKER toepassing in Discovery Studio 3.5 (Wu et al., 2003). 'n Maksimum van tien lukraak konformere is vir elke ligand gegenereer en die molekulêre dinamika bereken deur volgehoue verwarming- en verkoelingstadia, tot ' $n$ minimum bereik is. Die poses wat so verkry is, is geassesseer met behulp van die funksies PLP1, PLP2, PMF, PMF04, Jain, LigScore1, en LigScore2, gevolg deur samestelling van 'n 'konsensus' telling; verbindings met die hoogste tellings is uitgesoek vir opvolgwerk.

\section{In vitro sifting van voorkeur verbindings teen Plasmodium falciparum NF54 stam in die gametosietstadium}

Die antiplasmodiale toetse teen laat-stadium (IV-V) gametosiete is deur die SuidAfrikaanse Wetenskaplike en Nywerheidsnavorsingsraad (WNNR, Pretoria, Suid Afrika) se Molekulêre en Biomediese Tegnologieë groep uitgevoer, soos beskryf in (Reader et al., 2015).

\section{Resultate en bespreking Molekuulmodellering van PfCDPK4}

\section{Struktuurvoorspelling deur homologiemodellering}

Die volledige PfCDPK4 aminosuurvolgorde gevind in die UniProt Knowledgebase (UniProtConsortium, 2012) bestaan uit vyf domeine met ' $n$ totale lengte van 528 aminosuurresidue. Die proteïenkinase deel bestaan uit posisies 71 tot 329, met 'n domein bestaande uit 259 aminosure.

'n BLAST soektog met hierdie volgorde in die PDB (Protein Data Bank, http:/ / www.rcsb.org/pdb/) het 'n lys van 240 homoloë van die PfCDPK4 kinasedomein, met bekende proteïenstrukture, opgelewer. In hierdie lys is vyf template (Tabel 1) gevind met voldoende volgorde-identiteit en ooreenkoms met die PfCDPK4 volgorde om modelkwaliteit te verseker (Françoijs et al., 2000; Bordoli et al., 2008; Vyas et al., 2012). 'n Model met meer as 50\% templaat-teiken ooreenkoms dui aan dat die model akkuraat genoeg vir verdere ontwikkeling sal wees (Cavasotto en Phatak, 2009; Vyas et al., 2012). Kalmodulin-domein proteïenkinase 1 (PDB Id: 3ma6) van Toxoplasma gondii (TgCDPK1) is daarom as templaat gekies weens die hoë volgorde-identiteit (79\%) met PfCDPK4. Die templaat 3ma6 het ook 'n goeie resolusie van $2.5 \AA$ en die X-straal kristalstruktuur is vanaf die Protein Data Bank (http:/ / www.rcsb.org/pdb/) afgelaai. 
TABEL 1: Vyf templaatstrukture homoloog aan die PfCDPK4 kinasedomein, verkry deur middel van 'n BLAST soektog van die Proteïen Databank (PDB).

\begin{tabular}{|c|c|c|c|c|c|c|c|}
\hline PDB id & Volgorde-identiteit (\%) & Volgorde-lengte & Domein-lengte & Bit Score & E-Waarde & Resolusie (Å) & Organisme \\
\hline $3 \mathrm{ma6}$ (B) & 79 & 266 & 259 & 427.56 & $1.02 \mathrm{e}-120$ & 2.50 & T. gondii \\
\hline $3 n y v(A)$ & 78 & 457 & 259 & 426.79 & $1.85 e-120$ & 1.88 & T. gondii \\
\hline 2 wei $(A)$ & 68 & 278 & 257 & 362.07 & $6.61 \mathrm{e}-101$ & 1.65 & C. parvum lowa II \\
\hline $3 \operatorname{lij}(A)$ & 63 & 465 & 257 & 323.17 & $3.03 e-89$ & 1.90 & C. parvum lowa II \\
\hline $3 d x n(A)$ & 61 & 258 & 250 & 315.08 & $9.35 e-87$ & 2.17 & T. gondii \\
\hline
\end{tabular}

Vergelyking van die PfCDPK4 en TgCDPK1 aminosuurvolgordes het 78\% volgorde-identiteit en 90\% volgorde-ooreenkoms getoon (Figuur 1).

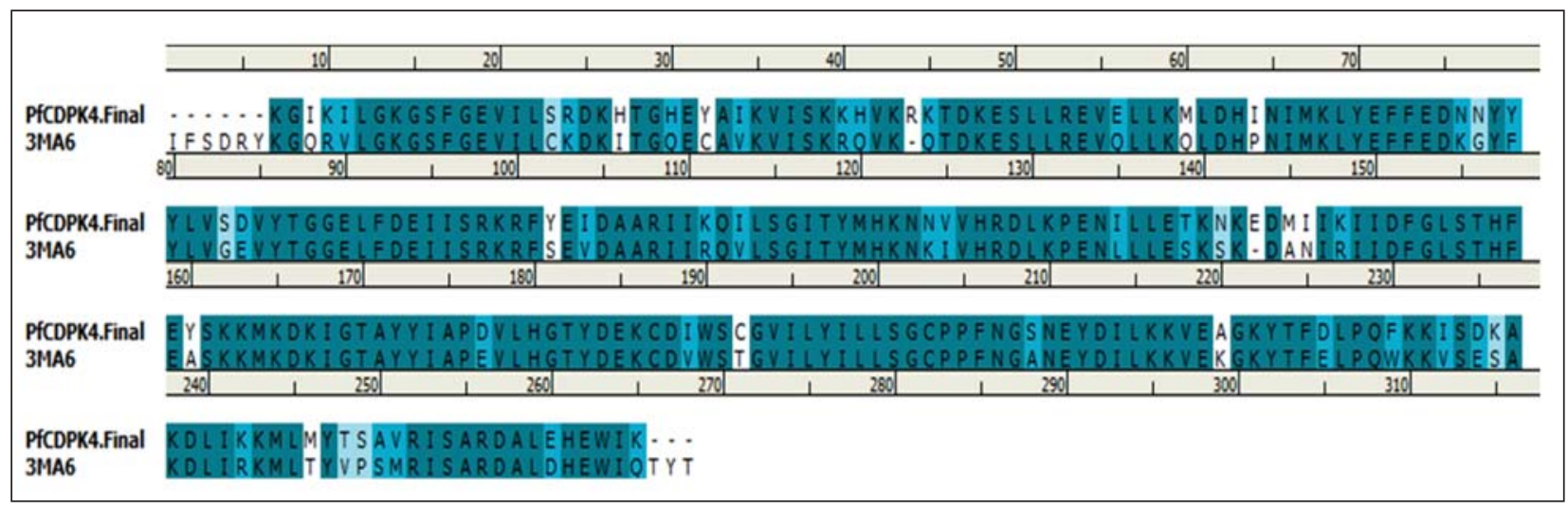

FIGUUR 1: Vergelyking van die PfCDPK4 en TgCDPK1 aminosuurvolgordes toon $78 \%$ volgorde-identiteit en $90 \%$ volgorde-ooreenkoms. Donkerblou kleur dui op gekonserveerde aminosuurresidue; Lig blou - sterk ooreenkoms; Flou blou - swak ooreenkoms; Wit - geen ooreenkoms.

Vervolgens is die 3D struktuurmodel van PfCDPK4 deur middel van die MODELER toepassing in Discovery Studio $V$ 3.5 gegenereer. Twintig PfCDPK4 modelle is gegenereer en die beste hiervan gekies op basis van die laagste DOPE (Discrete Optimized Protein Energy) telling en hoogste Verify telling (Tabel 2). Terwyl die DOPE telling van die PfCDPK4.F06 model die laagste was (-30 087) en die Verify telling van die PfCDPK4.F09 model die hoogste (114), is besluit om die modelle te verfyn, aangesien die Verify telling hoër as die verwagte (117.717) behoort te wees vir'n goeie kwaliteit model.

\section{PfCDPK4 modelstruktuur verfyning en validering vir stereochemiese kwaliteit}

Die Profile-3D lynplot (Figuur 2, blou lyn) vir die PfCDPK4 aminosuurresidue wys dat Leu130'n negatiewe Verify telling het, wat onreëlmatige vou van die proteïen veroorsaak (Huang et al., 2010a). Die Verify tellings vir Leu131, Asn135 and Val245 was ook naby 0. Gevolglik is verdere lusverfyning op hierdie residue uitgevoer. Na hierdie optimering van die PfCDPK4.F06 model het die DOPE en die Verify tellings heelwat verbeter (Tabel 3), terwyl die aminosure met lae

TABEL 2: Die tellings (DOPE en Verify tellings) van 3D struktuurmodelle van PfCDPK4 gegenereer deur MODELER.

\begin{tabular}{|c|c|c|c|c|}
\hline Naam & DOPE telling & Verify verwagte lae telling & Verify verwagte hoë telling & Verify telling \\
\hline PfCDPK4.F01 & -29966 & 52.973 & 117.717 & 112 \\
\hline PfCDPK4.F02 & -29834 & 52.973 & 117.717 & 108 \\
\hline PfCDPK4.F03 & -29830 & 52.973 & 117.717 & 106 \\
\hline PfCDPK4.F04 & -29576 & 52.973 & 117.717 & 110 \\
\hline PfCDPK4.F05 & -29639 & 52.973 & 117.717 & 108 \\
\hline PfCDPK4.F06 & -30087 & 52.973 & 117.717 & 113 \\
\hline PfCDPK4.F07 & -29718 & 52.973 & 117.717 & 106 \\
\hline PfCDPK4.F08 & -29819 & 52.973 & 117.717 & 112 \\
\hline PfCDPK4.F09 & -29944 & 52.973 & 117.717 & 114 \\
\hline PfCDPK4.F10 & -29937 & 52.973 & 117.717 & 110 \\
\hline PfCDPK4.F11 & -29792 & 52.973 & 117.717 & 108 \\
\hline PfCDPK4.F12 & -29924 & 52.973 & 117.717 & 108 \\
\hline PfCDPK4.F13 & -29416 & 52.973 & 117.717 & 103 \\
\hline PfCDPK4.F14 & -29651 & 52.973 & 117.717 & 107 \\
\hline PfCDPK4.F15 & -29933 & 52.973 & 117.717 & 112 \\
\hline PfCDPK4.F16 & -29719 & 52.973 & 117.717 & 107 \\
\hline PfCDPK4.F17 & -29612 & 52.973 & 117.717 & 103 \\
\hline PfCDPK4.F18 & -29767 & 52.973 & 117.717 & 110 \\
\hline PfCDPK4.F19 & -29678 & 52.973 & 117.717 & 106 \\
\hline PfCDPK4.F20 & -29786 & 52.973 & 117.717 & 112 \\
\hline
\end{tabular}


Verify tellings nou almal in die positiewe gebied voorkom (Figuur 2, rooi lyn), wat op die verbeterde kwaliteit van die finale model dui.

Passing van die finale PfCDPK4 modelstruktuur op die templaatstruktuur (TgCDPK1, PDB id: 3ma6, ketting B), toon die ooreenkomste tussen die twee strukture, met 'n gemiddelde afwyking (root mean square deviation, RMSD) van $0.92 \AA$ A (Figuur 3).

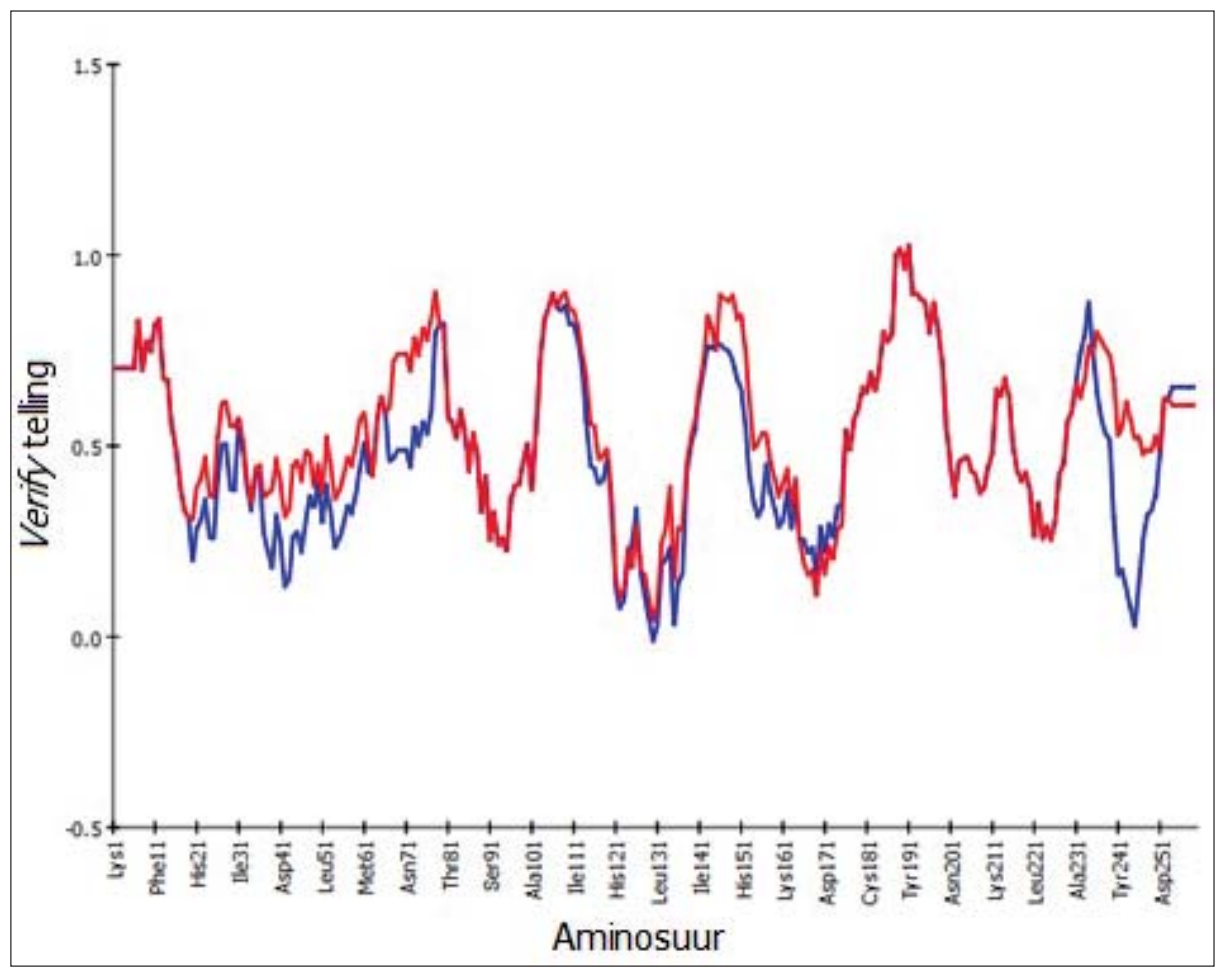

FIGUUR 2: Die aminosuur Verify telling vir die finale model ( $P f C D P K 4$, rooi) is beter as díe van die oorspronklike model (PfCDPK4.F06, blou), soos deur die Verify Protein (Profiles-3D) lyndiagramme getoon.

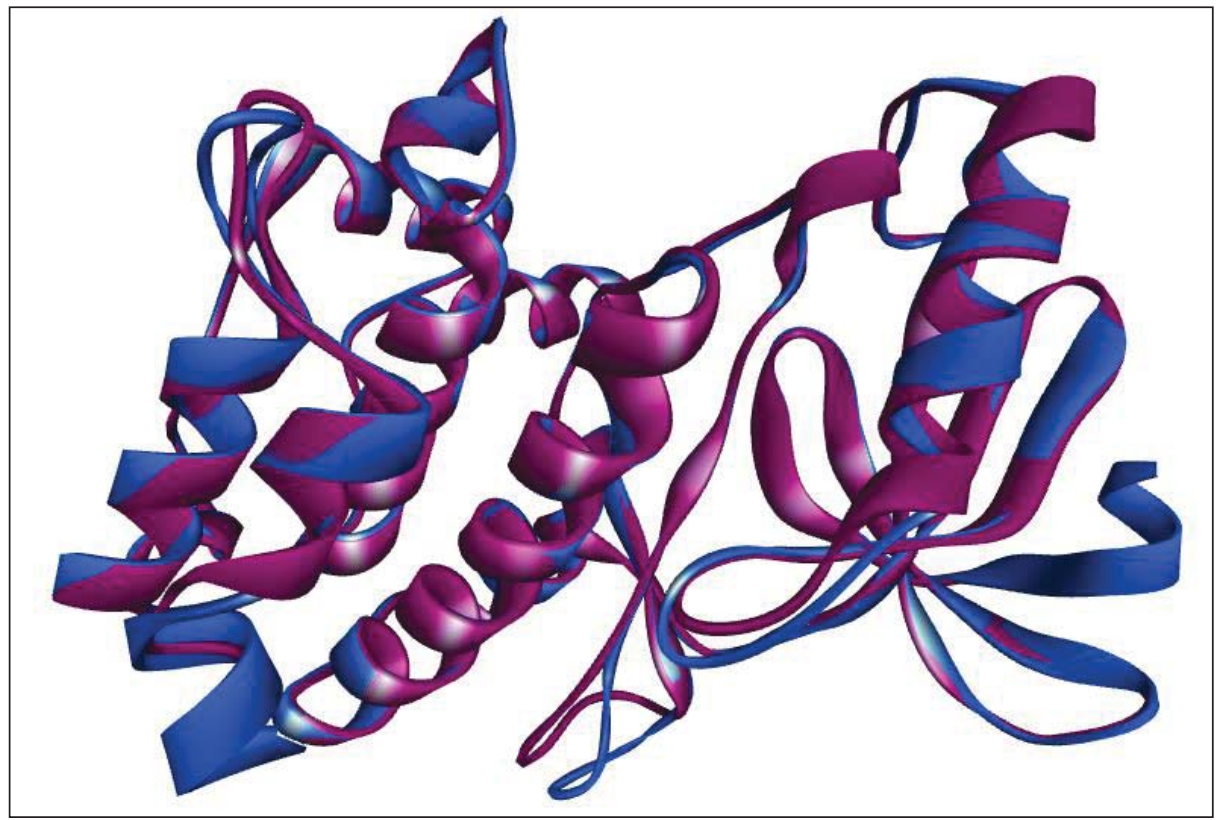

FIGUUR 3: Superponering van die PfCDPK4 homologiemodel (pers) en die TgCDPK1 (blou) strukture toon die ooreenkoms.

TABEL 3: Vergelyking van die verbeterde met die oorspronklike PfCDPK4 model. Die Ramachandran Z-telling bereken deur middel van die WHAT-IF toepassing (Hooft et al., 1997) meet die kwaliteit van die Ramachandran diagram (Figuur 4). Die tellings bevestig die kwaliteit van die finale model.

\begin{tabular}{lccc}
\hline \multicolumn{1}{c}{ Naam } & DOPE telling & Verify telling & Ramachandran Z-telling \\
\hline Oorspronklike Model (PfCDPK4.F06) & -30087 & 113 & 0.800 \\
Finale Model (PfCDPK4) & -30813 & 126 & 0.072 \\
\hline
\end{tabular}


Vir finale validering van die model is PROCHECK gebruik om die stereochemiese kwaliteit te bepaal met behulp van Ramachandran-diagramme wat die ruggraat dihedrale hoeke van al die aminosure in die struktuur wys en analiseer. Die Ramachandran-diagram wat met behulp van PROCHECK (Arnold et al., 2006), beskikbaar in die SWISS-MODEL Workspace (http:/ /swissmodel.expasy.org/ workspace/), saamgestel is (Figuur 4), toon aan dat 96\% van die $\phi$ en $\Psi$ hoeke van die aminosure in die finale PfCDPK4 model binne die gunstigste of lae-energie gebiede lê (Figuur 4: A, B, L), wat die kwaliteit van die model bevestig.

\section{Teiken en biblioteekvoorbereiding} PfCDPK4 modeloptimering en bindingsposisie

Die ATP-bindingsdomein van die modelstruktuur is geïdentifiseer deur middel van 'uitveër'-algoritmes. Sewe verskillende moontlikhede is gevind, waarvan een uitgestaan het (Figuur 5) op grond van bestaande kennis van ander proteïenkinase ATPbindingsposisies, soos bv. ERK2 (Extracellular Signal-Regulated Kinase 2) (Lounnas et al., 2013). Die ATP-bindingsposisies in verskillende kinases stem grootliks ooreen, wat selektiwiteitsprobleme kan veroorsaak (Huang et al., 2010a).

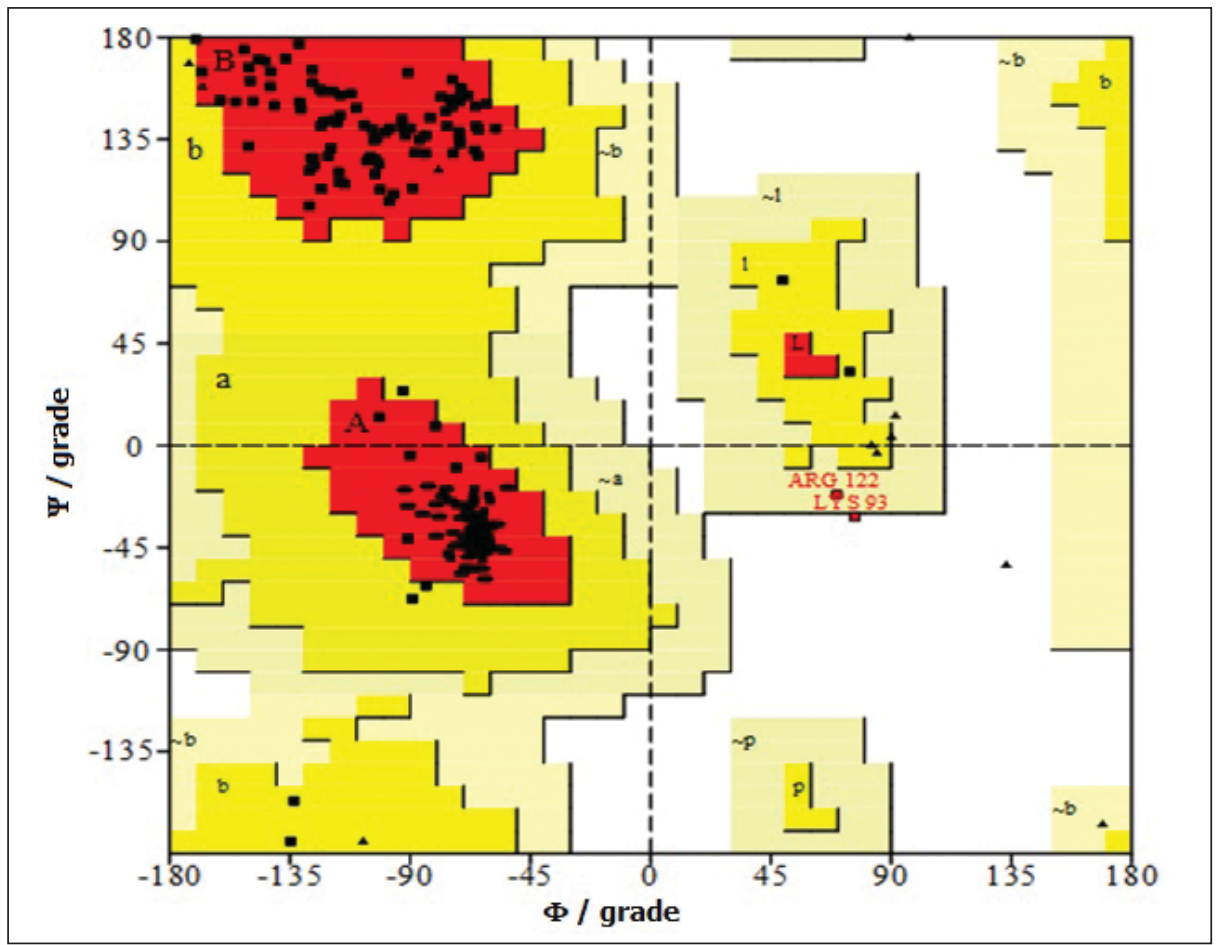

FIGUUR 4: Ramachandran-diagram van die PfCDPK4 model bereken deur middel van PROCHECK (Arnold et al., 2006). Rooi - gunstigste gebied; geel - toegelate gebied; liggeel - minder gunstig; wit - ongunstig.

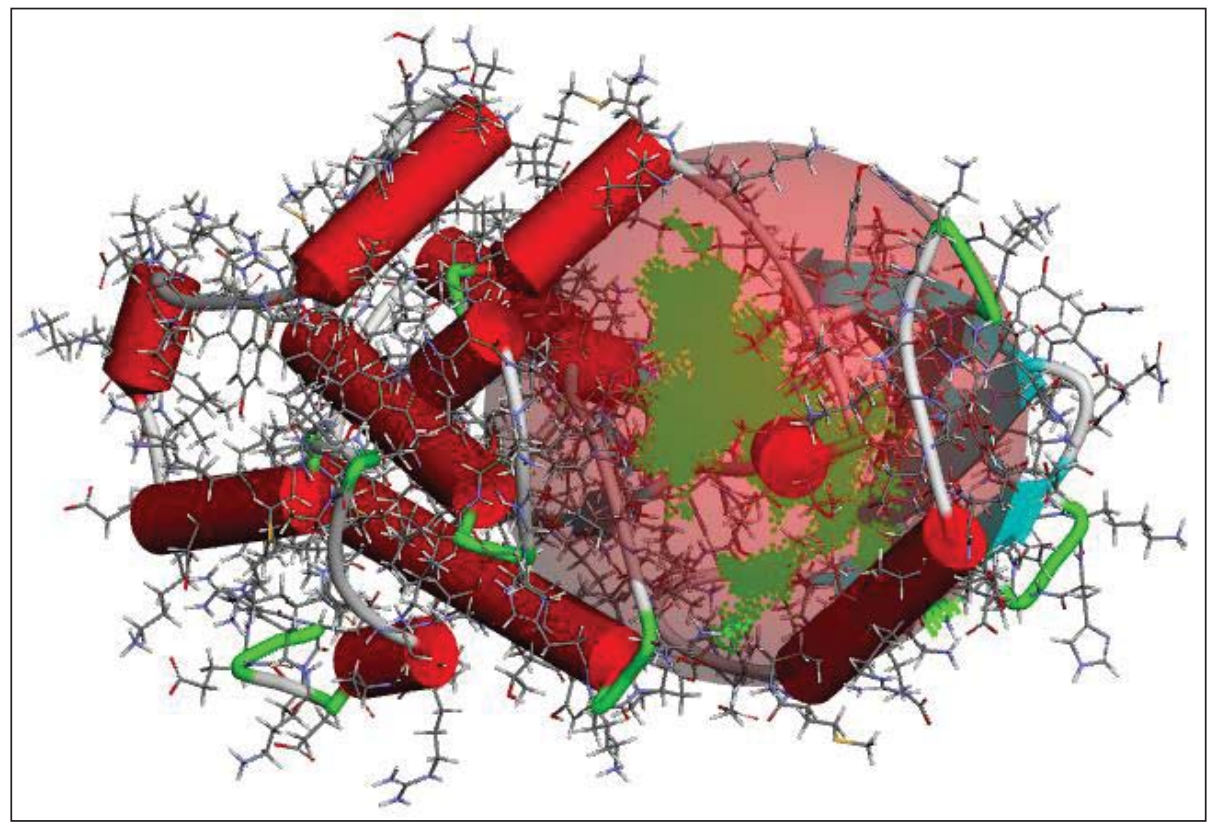

FIGUUR 5: Die finale PfCDPK4 modelstruktuur met sy ATP bindingsetel aangedui as groen kolle en die deursigtige omringende sfeer in ligrooi. 
Die volledige katalitiese domein van die kinase bestaan uit 259 residue (Aher en Roy, 2016 ) en het twee lobbe ( $N$-terminale lob en $C$-terminale lob) verbind deur'n segment wat 'n 'skarnierlus' genoem word. Die $N$-terminale lob is klein en bestaan hoofsaaklik uit vyf antiparallelle $\beta$-plate en 'n gekonserveerde $\alpha$-heliks, terwyl die $C$-terminale lob 'n $\alpha$-heliks vorm. Die gaping tussen die twee lobbe vorm die aktiewe gebied en bevat die residue wat direk betrokke is by katalise of ATP-binding (Schwartz en Murray, 2011). Vulpetti en Bosotti het 'n reeks van 38 residue binne die vyf ATP-bindingsdomeine gevind wat direk betrokke is by ATP binding deur die proteïenkinases (Vulpetti en Bosotti, 2004), terwyl Huang et al. bepaal het dat 36 residue betrokke is (Huang et al., 2010b). Die vyf ATP-bindingsdomeine is die adenosien bindingsgebied ('kinase-skarniergebied'), hidrofobiese gebied, fosfaatbindingsgebied, ribosebindingsgebied, en ingangsgebied. Met behulp van hierdie inligting was dit moontlik om die korrekte gebied te identifiseer.

\section{Bereiding en optimering van die Biofocus biblioteek, NSV versameling en kinase-inhibitore}

In die siftingsproses van die Biofocus biblioteek is 19351 verbindings wat aan die 'Lipinski Reël van 5' (Lipinski et al., 1997) voldoen, geselekteer. Die NSV versameling het 23 verbindings opgelewer. Voorbereiding van al drie versamelings het in totaal 83780 geoptimeerde strukture opgelewer, wat tautomere, stereoisomere, en geïoniseerde vorms insluit.

\section{Virtuele en in vitro sifting van klein molekule teen die moontlike teiken PfCDPK4}

\section{Virtuele sifting teen die PfCDPK4 3D modelstruktuur}

In silico sifting van die 83707 Biofocus strukture het 195 434 poses opgelewer, wat met behulp van die funksies PLP1, PLP2, PMF, PMF04, Jain, LigScore1, en LigScore2 (Krammer et al., 2005) geëvalueer is. ' $\mathrm{n}$ Konsensustelling is bereken om ligande te vind wat konsekwent hoë tellings in meer as een funksie behaal. Dit het 26 prioriteitverbindings opgelewer (Tabel 4, Figuur 6), wat geskeduleer is vir in vitro analise.

Die hoogste konsensustelling van 6 is vir verbindings TM1595, TM8696 en TM15669 verkry, en is as hoogsbelowend beskou.

Die mees-voorkomende aminosuurresidue wat aan waterstofbindings in hierdie 26 Biofocus-PfCDPK4 komplekse deelneem, is Asp145, Lys8, Glu84, Tyr80 en Lys125. Die interaksies van sommige van die PfCDPK4 model se aminosure met atome van drie geselekteerde verbindings word in Figuur 7 gewys.

Die dok van die 37 geoptimeerde NSVs teen PfCDPK4 het 308 poses opgelewer. Gebaseer op die konsensustellings is ses verbindings geselekteer (Tabel 5 en Figuur 8). Neurolenin C (Francois et al., 1996) en calothrixin A en B (Rickards et al., 1999) is van die treffers met die hoogste

TABEL 4: Dok-resultate teen die PfCDPK4 modelstruktuur vir die prioriteitverbindings uit die Biofocus biblioteek.

\begin{tabular}{|c|c|c|c|c|c|c|c|c|}
\hline Verbinding & LigScore1 & LigScore2 & PLP1 & PLP2 & Jain & PMF & PMF04 & Konsensus \\
\hline TM1595 & 4.77 & 3.59 & 102.27 & 103.59 & 7.29 & 117.29 & 66.76 & 6 \\
\hline TM1993 & 3.82 & 3.00 & 102.85 & 103.14 & 6.28 & 132.98 & 62.55 & 5 \\
\hline TM2078 & 4.28 & 3.88 & 90.44 & 94.28 & 6.49 & 132.18 & 66.39 & 5 \\
\hline TM2753 & -0.04 & -0.93 & 120.34 & 108.71 & 7.39 & 114.52 & 60.11 & 5 \\
\hline TM5949 & 4.30 & 5.74 & 111.52 & 104.54 & 7.74 & 90.67 & 42.12 & 5 \\
\hline TM6136 & 3.90 & 5.46 & 100.43 & 93.18 & 2.87 & 106.47 & 50.88 & 5 \\
\hline TM6139 & 4.27 & 4.93 & 102.28 & 90.35 & 5.17 & 119.36 & 64.92 & 5 \\
\hline TM7211 & 3.15 & 3.47 & 99.38 & 92.95 & 8.89 & 112.91 & 67.88 & 5 \\
\hline TM8696 & 3.73 & 3.67 & 111.20 & 97.13 & 6.69 & 115.14 & 74.85 & 6 \\
\hline TM9336 & -0.50 & -3.36 & 102.97 & 104.00 & 6.56 & 127.65 & 70.04 & 5 \\
\hline TM13502 & 4.61 & 4.75 & 98.21 & 95.67 & 4.31 & 108.29 & 42.51 & 5 \\
\hline TM14954 & 4.02 & 4.52 & 97.09 & 94.03 & 6.51 & 104.40 & 35.76 & 5 \\
\hline TM15195 & 2.68 & 0.94 & 100.73 & 102.02 & 7.21 & 129.57 & 59.23 & 5 \\
\hline TM15233 & 4.83 & 5.29 & 97.48 & 90.04 & 5.68 & 116.60 & 62.29 & 5 \\
\hline TM15235 & 4.55 & 4.80 & 103.18 & 95.55 & 6.32 & 115.46 & 46.57 & 5 \\
\hline TM15669 & 4.17 & 4.57 & 100.52 & 97.84 & 3.47 & 126.25 & 59.32 & 6 \\
\hline TM15928 & 3.97 & 3.38 & 98.84 & 98.10 & 7.33 & 82.90 & 65.13 & 5 \\
\hline TM15930 & 3.46 & 4.31 & 99.54 & 98.11 & 4.12 & 110.19 & 75.57 & 5 \\
\hline TM15940 & 2.18 & 2.89 & 99.48 & 96.33 & 6.65 & 114.89 & 66.61 & 5 \\
\hline TM16028 & 3.58 & 4.11 & 102.76 & 99.06 & 4.99 & 104.92 & 77.23 & 5 \\
\hline TM16037 & 4.28 & 3.28 & 106.62 & 105.12 & 7.49 & 68.36 & 64.65 & 5 \\
\hline TM16047 & 4.28 & 2.87 & 103.48 & 105.94 & 6.74 & 94.53 & 76.42 & 5 \\
\hline TM16054 & 4.49 & 4.41 & 101.51 & 101.00 & 7.73 & 86.10 & 64.18 & 5 \\
\hline TM16065 & 3.44 & 2.57 & 102.01 & 102.32 & 8.01 & 94.92 & 70.02 & 5 \\
\hline TM16098 & 4.00 & 4.23 & 97.01 & 101.90 & 7.11 & 102.03 & 70.72 & 5 \\
\hline TM19688 & 4.14 & 4.04 & 97.22 & 96.32 & 6.43 & 87.94 & 66.52 & 5 \\
\hline
\end{tabular}


<smiles>O=C(NCc1ccncc1)c1ccc2nc(C3OC(CO)C(O)C3O)[nH]c2c1</smiles>

TM1595<smiles>OCC1OC(c2nc3ccc(C(O)=Nc4ccc(N5CCOCC5)cc4)cc3[nH]2)CC1O</smiles>

OH

TM1993<smiles>COc1cc(-c2coc3c(C(=O)NCc4ccncc4)cccc23)ccc1O</smiles>

TM13502<smiles>COc1ccc(CC(N)c2csc(N=C(NCC3CCCCC3)NCC3CCCCC3)n2)cc1</smiles>

TM2078 TM2753 HO

TM14954<smiles>c1ccc(CN=c2[nH]c(NCC3CC3)nc3cc(-c4ccccc4)sc23)cc1</smiles>

TM5949<smiles>COc1ccc(/N=c2\nc(NCc3cccs3)[nH]c3ccsc23)cc1OC</smiles>

TM6136<smiles>O=CNc1cc(-c2cccs2)cn2ccnc12</smiles>

TM15195

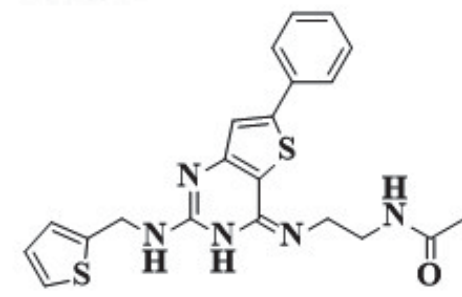

TM6139<smiles>O=C1COCc2ccc(-c3cnc4ccccc4c3)cc2N1CCN1CCOCC1</smiles>

TM7211<smiles>CCc1nc2ccc(C(=O)Nc3ccc(OC)c(OC)c3)cn2c1N(C)C(=O)C1CCCCC1</smiles>

TM9336<smiles>CC(=O)Nc1cc(-c2cccc(C(=O)N(C)C)c2)cn2c(-c3ccc(F)cc3)cnc12</smiles>

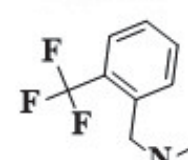<smiles>CC(C)=CCN1CCN2C(C(=O)Nc3ccc4c(c3)OCO4)=COC2=NC1=O</smiles>

TM8696<smiles>CC(=O)CCCCCCCCCO</smiles>
TM15930<smiles>COc1cccc(-c2nc3ccccc3c3[nH]ccc23)c1F</smiles>

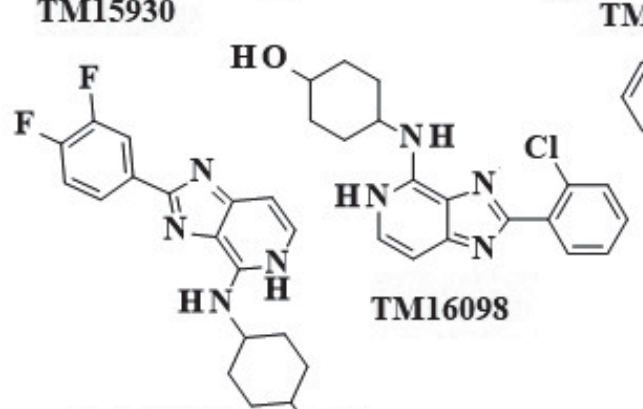

TM16047

OH<smiles>CC(=O)Nc1cccc(-c2cc(NC(C)=O)c3ncc(-c4cccc(C(C)=O)c4)n3c2)c1</smiles>

TM15235

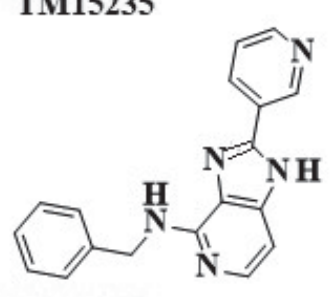

TM19688

TM15669 TM15928<smiles>C=C(/C=C/C=C/N(C)C)CNc1nccc2[nH]c(-c3ccc(F)c(F)c3)nc12</smiles>

TM16028<smiles>Fc1ccc(-c2nc3c(NCc4ccccc4)nccc3[nH]2)cc1F</smiles>

TM16054

FIGUUR 6: Strukture van die prioriteitverbindings verkry deur virtuele sifting van die geoptimeerde Biofocus biblioteek teen die PfCDPK4 modelstruktuur. 


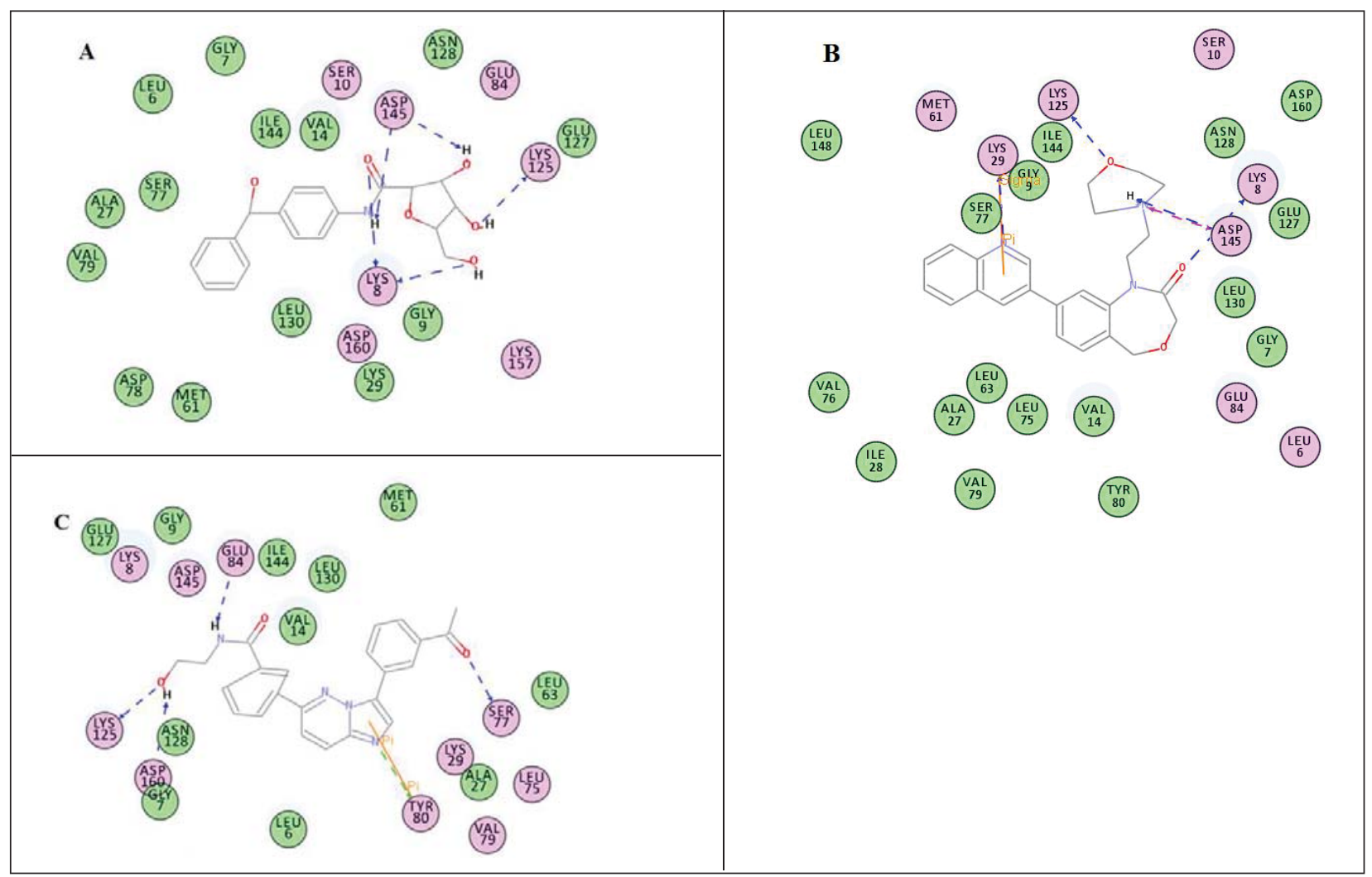

FIGUUR 7: Twee-dimensionele voorstellings toon die interaksies van die Biofocus verbindings met die hoogste moontlike affiniteit vir die PfCDPK4 aktiewe setel. Kompleks A: TM2078-PfCDPK4; kompleks B: TM7211-PfCDPK4; kompleks C: TM15669-PfCDPK4. Die blou en groen pyle dui op waterstofbindingsinteraksies, terwyl die oranje pyle $\pi-\sigma$ en $\pi-\pi$ interaksies aandui.

TABEL 5: Geselekteerde Natuurlike en Sintetiese Verbindings (NSVs) met die hoogste voorspelde bindingsaffiniteit vir die PfCDPK4 model. NeuroC; Neurolenin C; CaloA; Calothrixin A; CaloB; Calothrixin B; Compd3; Compd4; Compd5.

\begin{tabular}{|c|c|c|c|c|c|c|c|c|c|}
\hline Verbinding & LigScore1 & LigScore2 & PLP1 & PLP2 & Jain & PMF & PMF04 & $\begin{array}{c}\text { Konsensus- } \\
\text { telling }\end{array}$ & Struktuur \\
\hline NeuroC & 3.12 & 4.72 & 76.89 & 72.40 & 5.49 & 77.17 & 14.59 & 5 & \\
\hline Compd5 & 2.75 & 5.56 & 85.65 & 77.57 & 4.60 & 54.23 & 14.98 & 6 & \\
\hline Compd4 & 3.56 & 5.76 & 94.67 & 83.01 & 3.85 & 91.67 & 26.07 & 7 & \\
\hline Compd3 & 2.56 & 5.22 & 76.51 & 69.47 & 2.13 & 84.06 & 29.38 & 5 & \\
\hline CaloB & 2.95 & 5.44 & 77.24 & 71.24 & 3.02 & 90.05 & 38.30 & 5 & \\
\hline CaloA & 4.17 & 5.72 & 83.52 & 77.28 & 3.68 & 71.03 & 35.18 & 6 & \\
\hline
\end{tabular}




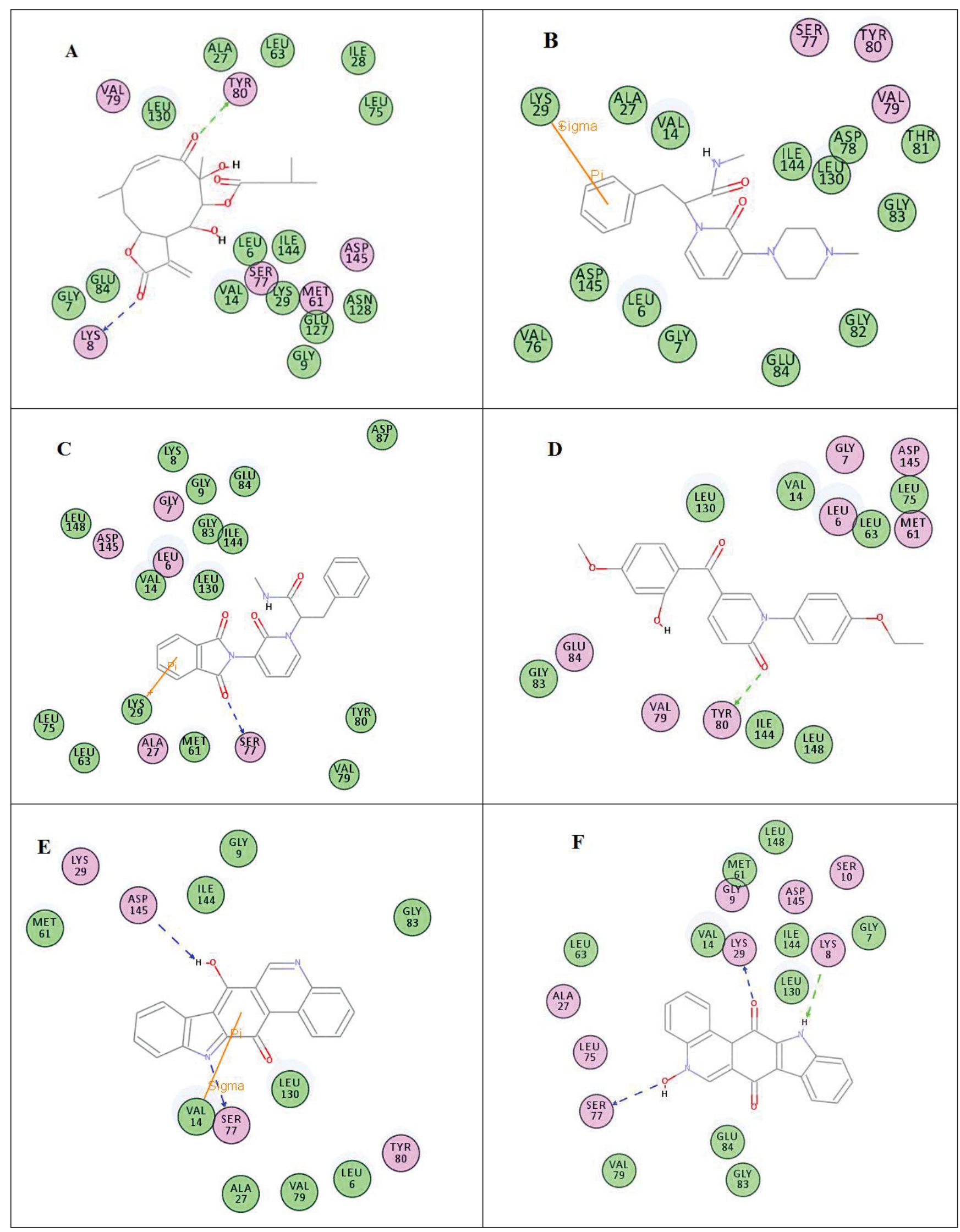

FIGUUR 8: Twee-dimensionele voorstellings toon die interaksies van die Natuurlike en Sintetiese Verbindings (NSVs) met die hoogste moontlike affiniteit vir die PfCDPK4 aktiewe posisie. Kompleks A: NeuroC; kompleks B: Compd5; kompleks C: Compd4; kompleks D: Compd3; kompleks E: CaloB; kompleks F: CaloA. Die blou en groen pyle dui op waterstofbindingsinteraksies, terwyl die oranje pyle $\pi-\sigma$ en $\pi-\pi$ interaksies aandui. 
TABEL 6: Vyf belowende verbindings / geselekteerde kinase-inhibitore vanuit die groep van 36 bekende kinase-inhibitore (Zhao et al., 2013) wat met die PfCDPK4 model gedok is.

\begin{tabular}{|c|c|c|c|c|c|c|c|c|c|}
\hline Verbinding $\mathrm{Nr}$ & LigScore1 & LigScore2 & PLP1 & PLP2 & Jain & PMF & PMF04 & $\begin{array}{c}\text { Konsensus- } \\
\text { telling }\end{array}$ & Struktuur \\
\hline 6450551 & 3.22 & 5.51 & 90.79 & 79.70 & 3.67 & 99.60 & 40.30 & 7 & \\
\hline 11626560 & 3.43 & 6.16 & 96.62 & 82.45 & 3.88 & 82.74 & 51.45 & 5 & \\
\hline 176870 & 3.34 & 5.41 & 85.66 & 79.34 & 2.44 & 65.39 & 32.29 & 5 & \\
\hline 10113978 & 3.44 & 5.49 & 94.38 & 86.11 & 6.01 & 101.59 & 50.07 & 6 & \\
\hline 42611257 & 4.37 & 5.74 & 81.07 & 79.53 & 5.22 & 87.50 & 43.14 & 5 & \\
\hline
\end{tabular}

voorspelde bindingsaffiniteit. Dit is natuurprodukte met bewese in vitro antimalaria-aktiwiteit, alhoewel hulle sellulêre teikens nog nie vasgestel is nie. Verdere ondersoek (bv. deur kristallisasie) word dus benodig om vas te stel of PfCDPK4 inderdaad die teiken van hierdie verbindings is.

Die 36 bekende kinase-inhibitore (Zhao et al. 2013) wat met die PfCDPK4 model gedok is, het 175 poses opgelewer. Die konsensustelling het vyf belowende verbindings (6450551, 11626560, 176870, 10113978 en 42611257) opgelewer (Tabel 6, Figuur 9). Hierdie verbindings was ongelukkig nie beskikbaar vir in vitro toetsing nie, maar die in silico resultate vir hierdie verbindings is belowend genoeg om hulle verder te ondersoek as moontlike middels wat PfCDPK4 sal teiken. 




FIGUUR 9: Twee-dimensionele voorstelling van interaksies van bekende kinase-inhibitore gedok met PfCDPK4. A: 6450551. B: 11626560. C: 176870 . D: 10113978. $E: 42611257$. Blou en groen pyle dui op waterstofbindingsinteraksies, terwyl die oranje pyle $\pi-\sigma$ en $\pi-\pi$ interaksies aandui. 


\section{In vitro sifting van Biofocus verbindings teen Plasmodium falciparum stam NF54}

Die aktiwiteit van CDPK4 word geassosieer met die gametosietstadium van die parasiet, en dus het ons besluit om die potensiaal van die 26 voorkeur verbindings om hierdie proteïen te teiken, te ondersoek. Die verbindings is in vitro getoets vir gametosiet-dodende aktiwiteit teen die Plasmodium falciparum NF54 stam, teen 'n konsentrasie van $5 \mu \mathrm{M}$ (Figuur 10). Verbindings wat minder as $20 \%$ inhibeer is as onaktief geklassifiseer, die wat minstens $50 \%$ inhibeer as marginaal aktief, en die wat meer as $70 \%$ inhibeer, as aktief. Van hierdie verbindings is drie as marginaal aktief geklassifiseer (TM2078 46\%, TM7211 47\%, en TM15669 42\%, Figuur 11), in ooreenstemming met hulle dok-resultate. Drie ander verbindings het meer as $20 \%$ inhibisie getoon: TM1595 37\%, TM2753 33\% en TM1993 27\% (Figuur 11). Die plasing van TM7211 in die model word in Figuur 12 getoon.

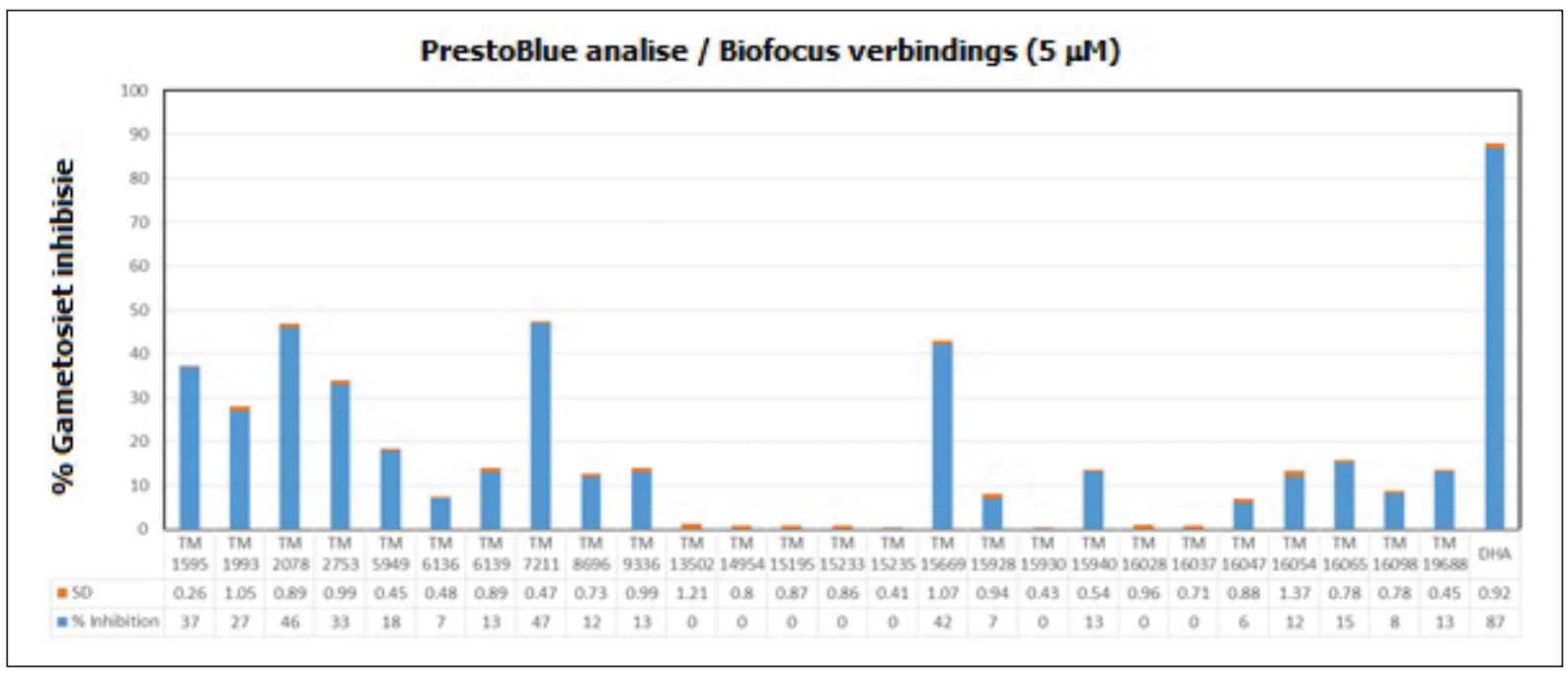

FIGUUR 10: In vitro siftingsresultate teen Plasmodium falciparum malaria stam NF54 vir 26 geselekteerde Biofocus verbindings.

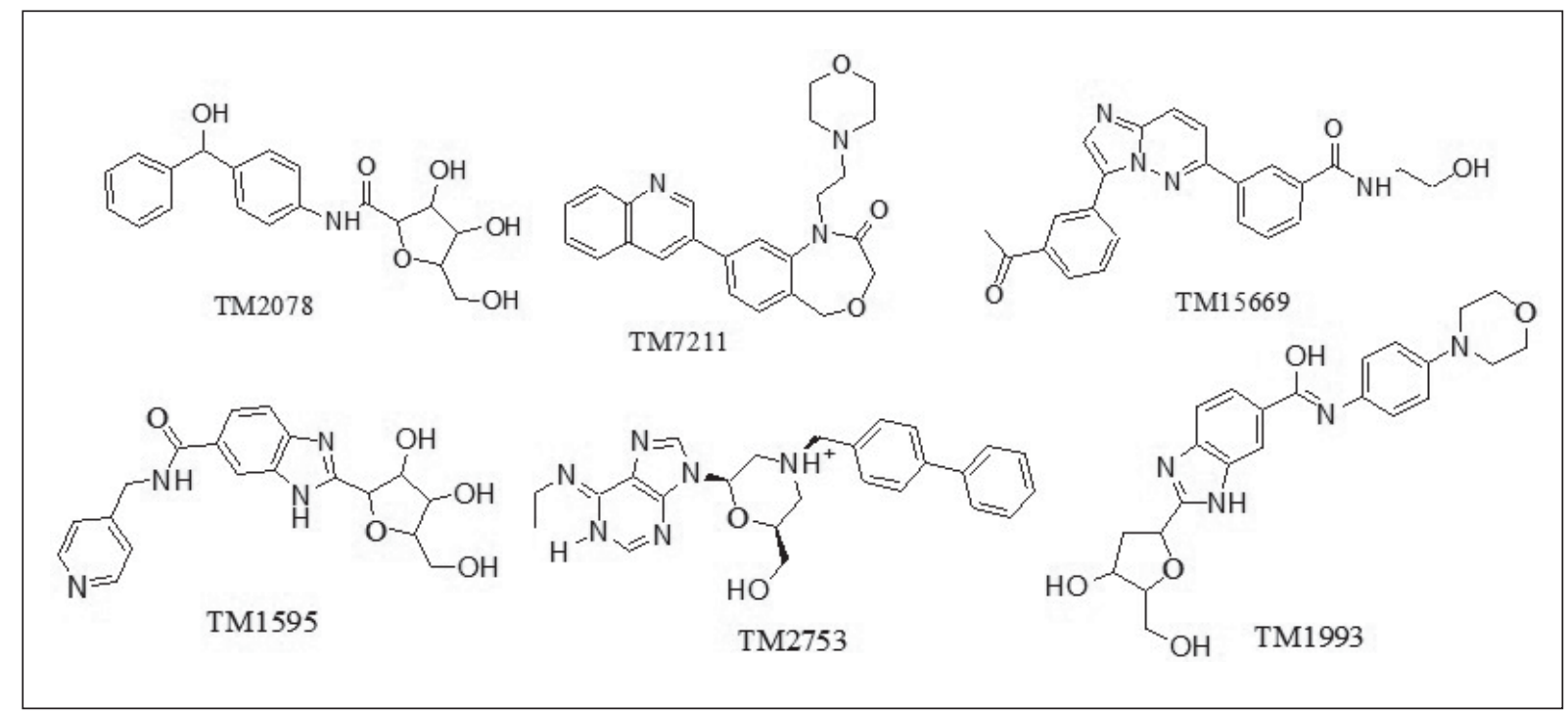

FIGUUR 11: Ses Biofocus verbindings met lae to marginale aktiwiteit teen Plasmodium falciparum malaria stam NF54. 


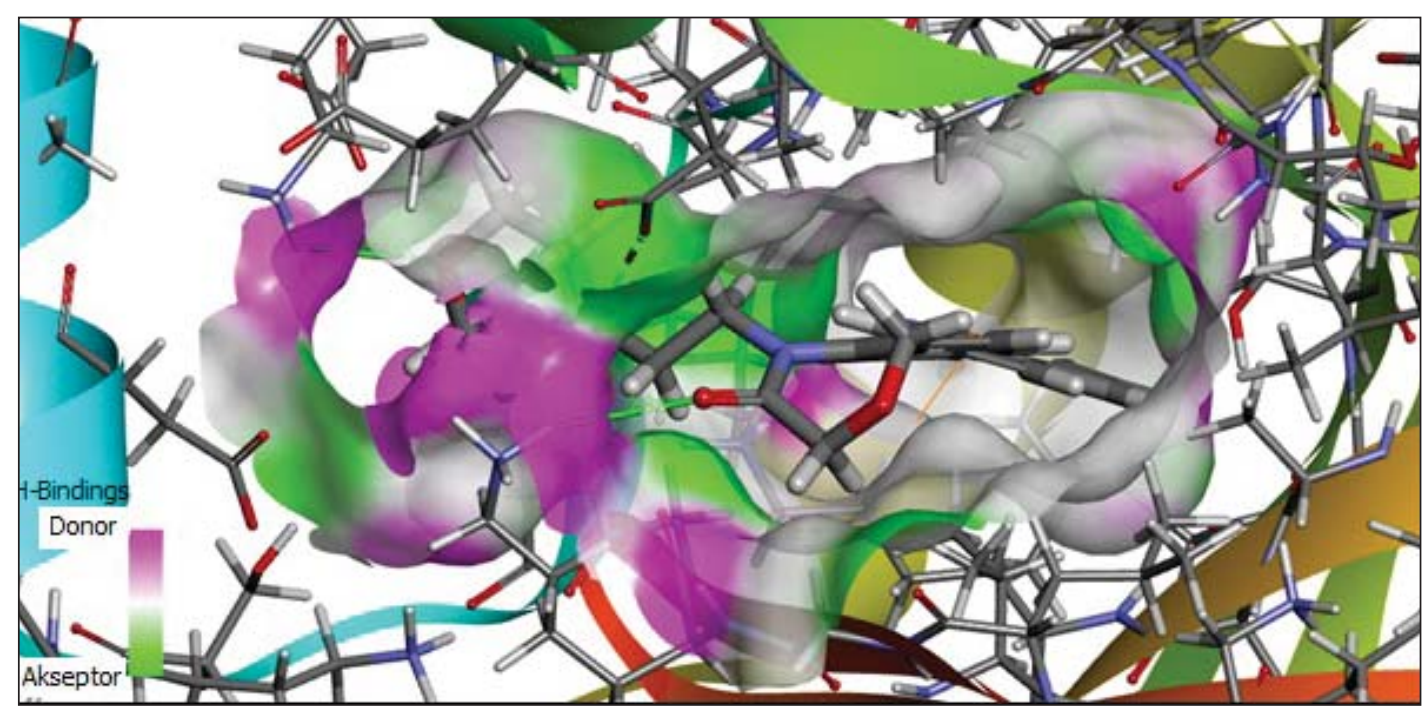

FIGUUR 12: Passing van verbinding TM2711 in die aktiewe setel van die PfCDPK4 model.

\section{Gevolgtrekkings}

Homologie-modellering is 'n betroubare en akkurate metode om die drie-dimensionele strukture van meeste proteïene te bepaal waarvoor eksperimenteelbepaalde strukture nog nie bekend is nie. Ten tyde van hierdie studie was die struktuur van PfCDPK4 nie in proteïenstruktuur-databasisse beskikbaar nie, sodat ons homologiemodellering toegepas het met die X-straal kristallografiese struktuur van TgCDPK1 (PDB kode: 3ma6-b) as 'n templaat om 'n geskikte PfCDPK4 struktuur te genereer vir geneesmiddelontdekking. Met 79\% identiteit was dit duidelik dat TgCDPK1 3ma6 die beste templaat is om die drie-dimensionele struktuur van PfCDPK4 op te baseer. Die verfynde struktuur het ook goeie stereochemiese gehalte getoon en is dus verder ontwikkel om die geskikste bindingsposisie te vind.

Die ligande wat in die dok-studies gebruik is, is eerstens gefiltreer met behulp van die Lipinski reëls, en vervolgens verder geselekteer deur middel van in silico sifting. Daar is aangetoon dat etlike Biofocus verbindings en sommige klinies-goedgekeurde kinase-inhibitore en natuurlike en sintetiese verbindings ' $n$ affiniteit vir die teiken het. In vitro sifting het die moontlike aktiwiteit van minstens drie verbindings teen Plasmodium falciparum stam NF54 aangetoon. Hierdie resultate bevestig die gebruik van die PfCDPK4 modelstruktuur as teiken in die soektog na nuwe verbindings vir die ontwikkeling van antimalaria geneesmiddels, veral deur die bestryding van transmissie van die siekte.

\section{Erkennings}

Die Nasionale Navorsingstigting en die Universiteit van Venda word bedank vir finansiële ondersteuning. Die Wetenskaplike en Nywerheidsnavorsingsraad (WNNRBiowetenskappe) word bedank vir gebruik van hulle hulpbronne, en die Sentrum vir Hoëverrigtingberekening
(Centre for High Performance Computing - CHPC) word bedank vir toegang tot die BIOVIA (voorheen Accelrys) Discovery Studio lisensie.

\section{Verwysings}

Accelrys Software, 2012. Discovery Studio Modeling Environment, in Release 3.5. Accelrys Sotiware Inc, San Diego. [http://www.Accelrys.com/products/ discovery-studio/]

Aher RB, Roy K. 2016. Exploring structural requirements for the inhibit on of Plasmodium falciparum calcium-dependent protein kinase-4 (PfCDPK-4) using mult ple in silico approaches. RSC Advances 6, 51957-51982.

Altschul SF, Madden TL, Schäffer AA, Zhang J, Zhang Z, Miller W, et al. 1997. Gapped BLAST and PSI-BLAST: a new generation of protein database search programs. BLAST and PSI-BLAST: a new generation
Nucleic Acids Research 25, 3389-3402.

Anastassiadis T, Deacon SW, Devarajan K, Ma H, Peterson JR. 2011. Comprehensive assay of kinase catalytic activity reveals features of kinase. Nature Biotechnology 29, 1039-1045.

Arnold K, Bordoli L, Kopp J, Schwede T. 2006. The SWISS-MODEL workspace: a webbased environment for protein structure homology modelling. Bioinformatics 22, 195-201.

Arnold K, Kiefer F, Kopp J, Battey JD, Podvinec M, Westbrook J, et al. 2009. The protein model portal. Journal of Structural and Functional Genomics 10, 1-8.

Bansal A, Singh S, More KR, Hans D, Nangalia K, Yogavel M, et al. 2013. Characterization of Plasmodium falciparum calcium-dependent protein kinase 1 (PfCDPK1) and its role in microneme secret on during erythrocyte invasion. Journal of Biological Chemistry 288, 1590-602.

Biamonte MA, Wanner J, Le Roch KG. 2013. Recent advances in malaria drug discovery. Bioorganic \& Medicinal Chemistry Letters 23, 2829-2843.

Billker O, Dechamps S, Tewari R, Wenig G, Franke-Fayard B, Brinkmann V. 2004 Calcium and a calcium-dependent protein kinase regulate gamete format on and mosquito transmission in a malaria parasite. Cell 117, 503-514.

Bordoli L, Kiefer F, Arnold K, Benkert P, Battey J, Schwede T. 2008. Protein structure homology modeling using SWISS-MODEL workspace. Nature Protocols 4, 1-13.

Brooks BR, Bruccoleri RE, Olafson BD, States DJ, Swaminathan S, Karplus M. 1983. CHARMM: A program for macromolecular energy, minimization, and dynamics calculations. Journal of Computational Chemistry 4, 187-217.

Cavasotto CN, Phatak SS. 2009. Homology modeling in drug discovery: current trends and applications. Drug Discovery Today 14, 676-683.

Chapman TM, Osborne SA, Bouloc N, Large JM, Wallace C, Birchall K, et al 2013. Substituted imidazopyridazines are potent and selective inhibitors of Plasmodium falciparum calcium-dependent protein kinase 1 (PfCDPK1) Bioorganic \& Medicinal Chemistry Letters 23, 3064-3069.

Deshpande N, Addess KJ, Bluhm WF, Merino-Ott JC, Townsend-Merino W, Zhang Q e et al. 2005. The RCSB Protein Data Bank: a redesigned query system and relational database based on the mmCIF schema. Nucleic Acids Research 33, D233-D237; http://www.rcsb.org/pdb/ 
Dorin-Semblat D, Carvalho, TG, Nivez M-P, Halbert J, Poullet P, Semblat J-P, et al. 2013. An atypical cyclin-dependent kinase controls Plasmodium falciparum proliferation rate. Kinome 1, 4-16

Françoijs CJJ, Klomp JPG, Knegtel RMA. 2000. Sequence annotation of nuclear receptor ligand-binding domains by automated homology modeling. Protein Engineering 13, 391-394.

Francois G, Passreiter CM, Woerdenbag HJ, Van Looveren M. 1996. Ant plasmodial activities and cytotoxic effects of aqueous extracts and sesquiterpene lactones from Neurolaena lobata. Planta Medica 62, 126-129.

Hooti RWW, Sander C, Vriend G. 1997. Objectively judging the quality of a protein structure from a Ramachandran plot. CABIOS Bioinformatics 13(4), 425-430.

Hovmoller S, Zhou T, Ohlson T. 2002. Conformations of amino acids in proteins. Acta Crystallographica Section D 58, 768-776.

Huang H-J, Yu HW, Chen C-Y, Hsu C-H, Chen H-Y, Lee K-J, et al. 2010. Current developments of computer-aided drug design. Journal of the Taiwan Institute of Chemical Engineers 41, 623-635.

Huang D, Zhou T, Lafleur K, Nevado C, Caflisch A. 2010. Kinase selectivity potential for inhibitors targeting the ATP binding site: a network analysis. Bioinformatics 26, 198-204.

Kang BS, Pugalendhi GK, Kim KJ. 2017. Binding direct on-based two-dimensiona flattened contact area computing algorithm for protein-protein interactions. Molecules 22(10), 1722. doi: 10.3390/molecules22101722

Karplus M. 2003. Molecular dynamics of biological macromolecules: a brief history and perspective. Biopolymers 68, 350-358. doi: 10.1002/Bip.10266.

Klein EY. 2013. Ant malarial drug resistance: a review of the biology and strategies to delay emergence and spread. International Journal of Antimicrobial Agents $41,311-317$

Krammer A, Kirchhoff PD, Jiang X, Venkatachalam CM, Waldman M. 2005. LigScore: a novel scoring function for predicting binding affinities. Journal of Molecula Graphics and Modelling 23, 395-407.

Kumar S, Kumar M, Ekka R, Dvorin JD, Paul AS, Madugundu AK, et al. 2017. PfCDPK1 mediated signaling in erythrocytic stages of Plasmodium falciparum. Nature Communications 8, Article 63.

Laskowski RA, MacArthur MW, Moss DS, Thornton JM, 1993. PROCHECK: a program to check the stereochemical quality of protein structures. Journal of Applied Crystallography 26, 283-291.

Lim DC, Cooke BM, Doerig C, Saeij JPJ. 2012. Toxoplasma and Plasmodium protein kinases: roles in invasion and host cell remodelling. International Journal for Parasitology 42, 21-32.

Lipinski CA, Lombardo F, Dominy BW, Feeney PJ. 1997. Experimental and computational approaches to estimate solubility and permeability in drug discovery and development settings. Advanced Drug Delivery Reviews 23 , 3-25.

Lounnas V, Ritschel T, Kelder J, McGuire R, Bywater R, Foloppe N. 2013. Current progress in structure-based rational drug design marks a new mindset in drug discovery. Computational and Structural Biotechnology Journal 5, 1-14.

Murray CJL, Rosenfeld LC, Lim SS, Andrews KG, Foreman KJ, Haring D, et al. 2012. Global malaria mortality between 1980 and 2010: A systematic analysis. The Lancet 379, 413-431.

Ojo KK, Pfander C, Mueller NR, Burstroem C, Larson ET, Bryan CM, et al. 2012. Transmission of malaria to mosquitoes blocked by bumped kinase inhibitors. The Journal of Clinical Investigation 122, 2301-2305.

Ojo KK, Eastman RT, Vidadala R, Zhang Z, Rivas KL, Choi R, et al. 2014. A specific inhibitor of PfCDPK4 blocks malaria transmission: chemical-genetic validation. Journal of Infectious Diseases 209, 275-284.

Ramachandran GN, Ramakrishnan C, Sasisekharan V. 1963. Stereochemistry of polypeptide chain configurations. Journal of Molecular Biology 7, 95-99.

Ranjan R, Ahmed A, Gourinath S, Sharma P. 2009. Dissect on of mechanisms involved in the regulation of Plasmodium falciparum calcium-dependent protein kinase 4. Journal of Biological Chemistry 284, 15267-15276.

Reader J, Botha M, Theron A, Lauterbach SB, Rossouw C, Engelbrecht D, et al. 2015 Nowhere to hide: interrogating different metabolic parameters of Plasmodium falciparum gametocytes in a transmission blocking drug discovery pipeline towards malaria elimination. Malaria Journal 14, 213.

Regad L, Martin J, Nuel G, Camproux AC2010. Mining protein loops using a structural alphabet and statistical exceptionality. BMC Bioinformatics 11, 75 .

Rickards RW, Rothschild JM, Willis AC, De Chazal NM, Kirk J, Kirk K, et al. 1999 Calothrixins A and B, novel pentacyclic metabolites from Calothrix cyanobacteria with potent activity against malaria parasites and human cancer cells. Tetrahedron 55, 13513-13520.

Schwartz PA, Murray BW. 2011. Protein kinase biochemistry and drug discovery. Bioorganic Chemistry 39, 192-210.

Šali A, Potterton L, Yuan F, Van Vlijmen H, Karplus M. 1995. Evaluation of comparative protein modeling by MODELER. Proteins: Structure, Function, and Bioinformatics 23, 318-326, 1995

Shen MY, Šali A. 2006. Statistical potential for assessment and prediction of protein structures. Protein Science 15, 2507-2524.

Taha MO, Habash M, Khanfar MA. 2014. The use of docking-based comparative intermolecular contacts analysis to identify optimal docking conditions within glucokinase and to discover of new GK activators. Journal of Computer-Aided Molecular Design 28, 509-547; doi10.1007/s10822-014-9740-4

Tang K, Zhang J, Liang J. 2014. Fast protein loop sampling and structure predic on using distance-guided sequential chain-growth Monte Carlo Method. PLoS Computational Biology 10, 1-16.

Tewari R, Straschil U, Bateman A, Bohme U, Cherevach I, Gong P, et al. 2010 The systematic functional analysis of Plasmodium protein kinases identifies essential regulators of mosquito transmission. Cell Host \& Microbe 8, 377-387.

Thompson JD, Higgins DG, Gibson TJ. 1994. CLUSTAL W: improving the sensitivity of progressive multiple sequence alignment through sequence weight ng, position-specific gap penalties and weight matrix choice. Nucleic Acids Research 22, 4673-4680.

UniProt Consortium, 2012. Reorganizing the protein space at the Universal Protein Resource (UniProt). Nucleic Acids Research 40, D71-5; hк p://www.uniprot. org/uniprot/Q8IBS5.

Venkatachalam CM, Jiang X, Oldfield T, Waldman M. 2003. LigandFit: a nove method for the shape-directed rapid docking of ligands to protein active sites. Journal of Molecular Graphics \& Modelling 21, 289-307.

Vidadala RS, Ojo KK, Johnson SM, Zhang Z, Leonard SE, Mitra A. et al. 2014 Development of potent and selective Plasmodium falciparum calciumdependent protein kinase 4 (PfCDPK4) inhibitors that block the transmission of malaria to mosquitoes. European Journal of Medicinal Chemistry 74, 562573.

Vulpetti A, Bosotti R. 2004. Sequence and structural analysis of kinase ATP pocket residues. Farmaco 59, 759-65.

Vyas VK, Ukawala RD, Ghate M, Chintha C, 2012. Homology modeling a fast tool for drug discovery: current perspectives. Indian Journal of Pharmaceutical Sciences $74,1-17$.

WHO (World Health Organization), 2011. Global plan for artemisinin resistance containment (GPARC). WHO, Geneve.

WHO (World Health Organizatiuon), 2016. World Malaria Report 2016 Fact Sheet. WHO, Geneve.

WHO (World Health Organization), 2017. World Malaria Report. WHO, Geneve.

Wu G, Robertson DH, Brooks CL, Vieth M. 2003. Detailed analysis of grid-based molecular docking: A case study of CDOCKER - A CHARMm-based MD docking algorithm. Journal of Computational Chemistry 24, 1549-1562.

Yu H, Jin H, Sun L, Zhang L, Sun G, Wang Z, et al. 2013. Toll-like receptor 7 agonists: chemical feature based pharmacophore identification and molecular docking studies. PLoS One 8, 1-11.

Zhao HY, Wei H, Wang X. 2013. The reciprocal interaction of small molecule protein kinase inhibitors and ATP-binding cassette transporters in targeted cancer therapy. Journal of Cancer Research Updates 2, 68-86. 